\title{
Significance of the measurement of uric acid fractional clearance in diuretic induced hyponatraemia
}

\author{
M. Sonnenblick and A.J. Rosin \\ Geriatric Department, Shaare Zedek Medical Center, P.O.B. 293, Jerusalem 91-000, Israel
}

\begin{abstract}
Summary: The biochemical features of severe hyponatraemia due to thiazide administration in 7 nonoedematous patients were compared with those in hyponatraemia due to frusemide. Hypouricaemia has been shown to occur in hyponatraemia due to the syndrome of inappropriate antidiuretic hormone activity and this was measured along with fractional uric acid clearances in all the patients. Five of the patients had been on thiazides (or hydrochlorothiazide with amiloride) for only a few days to a few weeks. Fractional uric acid clearance was elevated and serum uric acid levels were low in five of them and returned to the normal range on restoration of serum sodium to normal. By contrast, the patients on frusemide did not show any abnormality in fractional uric acid clearance at any stage.

These results are consistent with excess ADH activity as having caused hyponatraemia induced by thiazides in 5 of the 7 cases, whereas frusemide caused a sodium depletion syndrome. Treatment in the former cases is by water restriction, and in frusemide-induced salt depletion by saline supplementation.
\end{abstract}

\section{Introduction}

In patients diagnosed on clinical and biochemical grounds as having the syndrome of inappropriate antidiuretic hormone activity (SIADH), Beck (1979) showed that hypouricaemia was a marked feature in contrast to those with hyponatraemia from other causes. Since Beck's observation the coexistence of hypouricaemia and hyponatraemia has been used as a simple means to distinguish SIADH from other causes of hyponatraemia (Weinberger et al., 1982; Passamonte, 1984). It appears that the low serum uric acid levels are due to an increase in fractional urinary excretion of uric acid.

A number of authors have suggested inappropriate $\mathrm{ADH}$ secretion as a cause for hyponatraemia induced by thiazides (Fichman et al., 1971; Horowitz et al., 1972; Luboshitzky et al., 1978; Husby \& Marthedal, 1981; Booker, 1984). In the present investigation, fractional uric acid clearances were used to determine whether diuretic-induced hyponatraemia could be due to excess ADH activity or to other causes.

\section{Patients and methods}

Thirteen patients presenting with severe degrees of hyponatraemia (plasma sodium less than $120 \mathrm{mmol} / \mathrm{l}$ )

Correspondence: M. Sonnenblick M.D.

Accepted: 11 December 1985 were studied. Seven were taking thiazide diuretics; of these, five had been on the drug for less than 3 weeks, whilst the two others had been taking chlorothiazide for one year. In five patients, the only indication for thiazide administration was hypertension. The other six patients had been taking frusemide for many months.

In all thirteen patients there was no oedema and no evidence, clinically or biochemically, of renal, adrenal or thyroid insufficiency. None was receiving other drugs which could interfere with ADH or water excretion mechanisms. On admission diuretics were discontinued and fluid intake was restricted to less than a litre per day.

Studies on the urine fractional clearance of uric acid were carried out on the morning after the diagnosis of hyponatraemia and later after the diuretics had been discontinued and serum sodium was restored to normal. All the patients had an indwelling catheter. Urine was discarded at $07.00 \mathrm{~h}$ and the test urine was collected between $07.00-09.00 \mathrm{~h}$, and blood samples were taken at $08.00 \mathrm{~h}$ with the patients fasting. The excreted fraction of filtered uric acid was calculated as (urine/serum) concentration of uric acid multiplied by (serum/urine) concentration of creatinine times 100 . The chemical measurements were carried out by standard techniques on the hospital laboratory autoanalyser. The results are expressed as mean \pm standard error. Statistical analysis was performed by Wilcoxon's and Mann-Whitney tests.

C The Fellowship of Postgraduate Medicine, 1986 


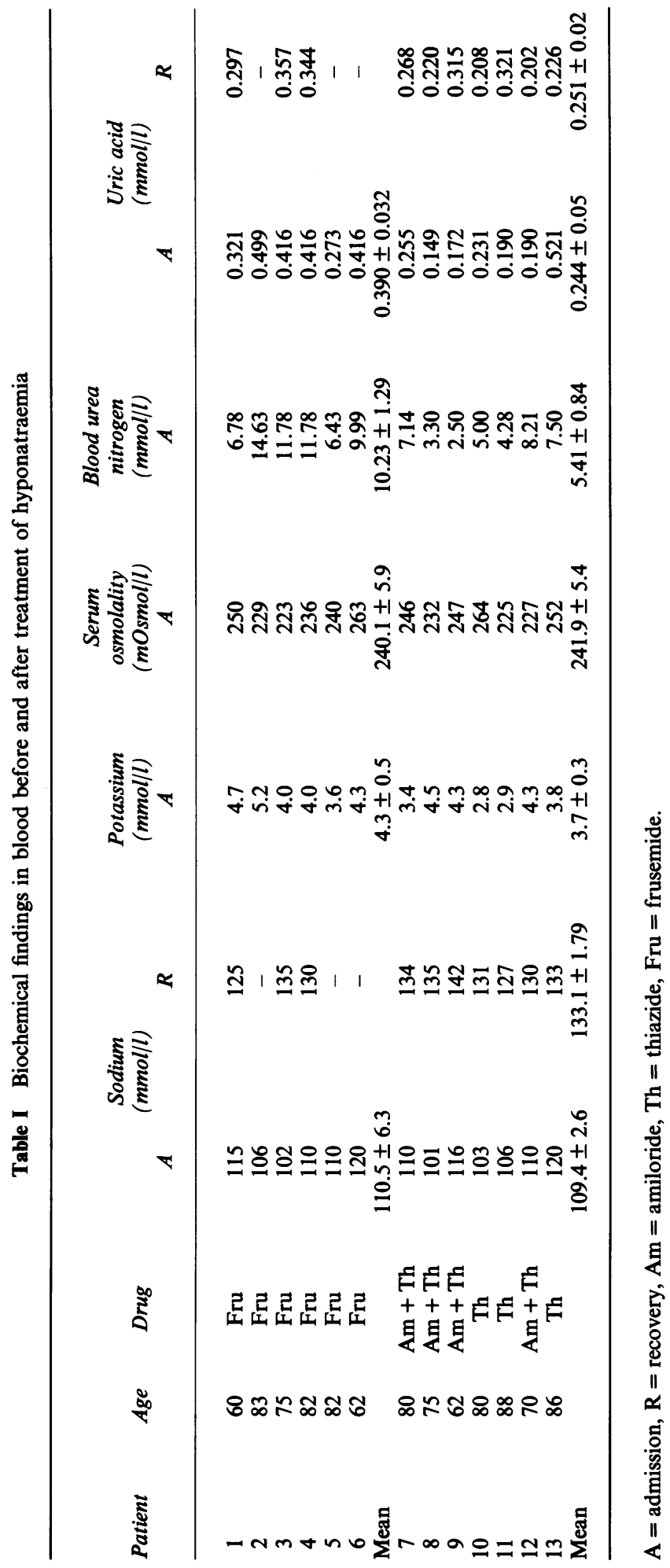




\section{Results}

Table I summarizes the serum concentrations of sodium, potassium, uric acid and blood urea nitrogen. In all cases, the serum osmolality was low (range 223-264 mOsm) during the hyponatraemic phase. Urine osmolality in four patients on thiazides was inappropriately high (range $430-480 \mathrm{mOsm}$ ).

The mean serum uric acid level in the six patients who were taking frusemide was $0.39 \pm 0.032 \mathrm{mmol} / 1$. The fractional uric acid clearance of $12.8 \pm 1 \%$ was within normal limits during the hyponatraemic phase. (The normal range of the excreted fraction of uric acid is 6 to $12 \%$ ) (Berger \& Yu, 1975) (Table II). In contrast to these results, in five patients with hyponatraemia from thiazides (Patients 7-11) the ratio of excreted to filtered fraction of uric acid was significantly increased $(34 \pm 9.8)$ and became normal $(9.6 \pm 1.7 \%)$ after correction of the serum sodium (Table II). The mean serum uric acid in these five patients was $0.199 \pm 0.19 \mathrm{mmol} / \mathrm{l}$ and the mean blood urea nitrogen concentration was $4.44 \pm 0.79 \mathrm{mmol} / 1$. In the other two patients on thiazides (patients 12 and 13) fractional uric acid clearance was nearly normal during the hyponatraemia (14 and 13\% respectively).

Table II Fractional uric acid clearance before and after water restriction

\begin{tabular}{ccc} 
& \multicolumn{2}{c}{ Uric acid clearance } \\
\cline { 2 - 3 } Patient & creatinine clearance \\
A & $R$ \\
\hline
\end{tabular}

\begin{tabular}{lcc}
1 & 15 & 17 \\
2 & 9 & - \\
3 & 12 & 11 \\
4 & 12 & 9.0 \\
5 & 16 & - \\
6 & 13 & - \\
Mean & $* 12.8 \pm 1.0$ & \\
7 & 26 & 15 \\
8 & 24 & 5 \\
9 & 73 & 8 \\
10 & 28 & 8 \\
11 & 19 & 12 \\
12 & 13 & 11 \\
13 & 14 & - \\
Mean & $* 28.1 \pm 7.8$ & $* * 9.8 \pm 1.4$ \\
\hline
\end{tabular}

Patients 1-6: frusemide treatment; patients 7-13: thiazide treatment.

${ }^{*} P=0.014 ;{ }^{* *} P<0.03$.

\section{Discussion}

A common train of events initiated by thiazides and other diuretics is an increase in sodium excretion and a depletion in plasma volume, often accompanied by a rise in the blood urea level. The serum uric acid is frequently elevated and this is attributed to inhibition of uric acid secretion in the proximal tubule. These changes may be accompanied by mild to moderate hyponatraemia if diuretic therapy is prolonged or intensive.

The clinical picture and pathogenesis of the condition of the patients on thiazides described above was obviously different. In all of them there was severe hyponatraemia and in five of the seven a short clinical history of thiazide intake. The serum uric acid was lower than normal in six and the investigation showed significantly elevated fractional uric acid clearance in five of them. The blood urea nitrogen level in five of the seven patients on thiazides was low normal in contrast to the elevated level in those taking frusemide.

Severe hyponatraemia associated with diuretic treatment may occur for a number of reasons. Chronic loss of sodium without adequate replacement may cause hyponatraemia as in patients on a low sodium diet. The diluting capacity of the distal tubule is impaired by the action of thiazide. The glomerular filtrate is decreased due to hypovolaemia consequent on the diuretic action; decreased free water clearance resulting from this brings about hyponatraemia. Similarly, the hypovolaemia may stimulate ADH activity, and thereby increase reabsorption of water. A further reason for hyponatraemia is seen in states of prolonged potassium loss in the urine as a consequence of which sodium and water may move into the cells, causing a lowering of serum sodium levels.

Five of the patients on thiazides resemble those described by Fichman et al. (1971), Husby \& Marthedal (1981) and Booker (1984), in whom hyponatraemia occurred within a short time of thiazide administration. Rechallenge by a single dose of hydrochlorothiazide again caused a large fall in serum sodium in some patients (Fichman et al., 1971), and in one of our patients who was thus re-challenged, there was a reduction of serum sodium of $16 \mathrm{mmol} / \mathrm{l}$ within 24 hours. SIADH was suggested as a possible mechanism, and these authors indeed found raised serum levels of ADH in all the patients tested (Fichman et al., 1971; Husby \& Marthedal, 1981). Our finding of increased fractional uric acid clearance in five of the thiazide-treated patients is a strong indication of excess ADH activity (Beck, 1979). Correction of the hyponatraemia resulted in a return of the fractional uric acid clearance to normal. Experimental support for this connection was demonstrated by the occurrence of increased uric acid clearance in water loaded subjects who were given vasopressin (Mees et 
al., 1971). Therefore it appears that in certain patients excess ADH activity is an important contributing factor to the development of hyponatraemia associated with thiazide administration.

By contrast, in all the patients with hyponatraemia following treatment with frusemide, the fractional uric acid clearance was normal, and the probable explanation is sodium depletion through diuretic natriuresis. In the two thiazide treated patients with normal fractional uric acid clearance it is likely that the sodium loss along with reduced water clearance occurred through non-ADH dependent mechanisms. A similar explanation of sodium loss was postulated

\section{References}

ASHRAF, N., LOCKSLEY, R. \& ARIEFF, A. (1981). Thiazide induced hyponatraemia associated with death or neurologic damage in outpatients. American Journal of Medicine, 70, 1163.

BECK, L. (1979). Hypouricemia in syndrome of inappropriate ADH. New England Journal of Medicine, 301, 528.

BERGER, L.S. \& YU, T. (1975). Renal function in gout. American Journal of Medicine, 59, 605.

BOOKER, J.S. (1984). Severe symptomatic hyponatraemia in elderly outpatients: the role of thiazide therapy and stress. Journal of the American Geriatric Society, 32, 108.

FICHMAN, M.P., VORRHERR, H., KLEEMAN, C.R. \& TELFER, N. (1971). Diuretic induced hyponatraemia. Annals of Internal Medicine, 75, 853.

HOROWITZ, J., KEYNAN, A. \& BEN-ISHAY, D. (1972). Syndrome of inappropriate ADH secretion induced by cyclothiazide. Journal of Clinical Pharmacology, 12, 337.

HUSBY, S. \& MARTHEDAL, N.J. (1981). Hyponatremia due by Ashraf et al. (1981) in their patients with severe hyponatraemia following thiazide treatment in 2 of whom serum ADH levels were normal.

Since increased fractional uric acid clearance points to excess ADH activity, the treatment in such hyponatraemic patients should be by the induction of a negative water balance and not by attempting to restore a sodium deficit which probably does not exist. The hyponatraemia will generally be corrected within 48-72 hours and the increased fractional uric acid clearance drops to normal when the serum sodium rises to normal levels.

to thiazide diuretic. Acta Medica Scandinavica, 210, 523.

LUBOSHITZKY, R., TAL-OR, Z. \& BARZILAI, D. (1978). Chlorthalidone induced syndrome of inappropriate secretion of antidiuretic hormone. Journal of Clinical Pharmacology, 18, 336.

MEES, E.J., vAN ASSENDALFT, P.P. \& NIEUWENHINS, M.G. (1971). Elevation of uric acid clearance caused by inappropriate antidiuretic hormone secretion. Acta Medica Scandinavica, 189, 69.

PASSAMONTE, P.M. (1984). Hypouricemia, inappropriate secretion of antidiuretic hormone and small cell carcinoma of the lung. Archives of Internal Medicine, 144, 1569.

WEINBERGER, A., SANTO, M., SOLOMON, F., SHALIT, M., PINKHAS, J. \& SPERLING, O. (1982). Abnormality in renako urate handling in the syndrome of inappropriate secretion of antidiuretic hormone. Israel Journal of Medical Sciences, 18, 711. 